\title{
Simulating sub-Milankovitch climate variations associated with vegetation dynamics
}

\author{
E. Tuenter ${ }^{1,2}$, S. L. Weber ${ }^{1}$, F. J. Hilgen ${ }^{2}$, and L. J. Lourens ${ }^{2}$ \\ ${ }^{1}$ Royal Netherlands Meteorological Institute (KNMI), P.O. Box 201, 3730 AE De Bilt, The Netherlands \\ ${ }^{2}$ Department of Earth Sciences, Faculty of Geosciences, Utrecht University, Budapestlaan 4, 3584 CD Utrecht, The \\ Netherlands
}

Received: 11 August 2006 - Published in Clim. Past Discuss.: 11 September 2006

Revised: 30 January 2007 - Accepted: 13 March 2007 - Published: 22 March 2007

\begin{abstract}
Climate variability at sub-Milankovitch periods (between 2 and $15 \mathrm{kyr}$ ) is studied in a set of transient simulations with a coupled atmosphere/ocean/vegetation model of intermediate complexity (CLIMBER-2). Focus is on the region influenced by the African and Asian summer monsoon. Pronounced variations at periods of about $10 \mathrm{kyr}$ (Asia and Africa) and about $5 \mathrm{kyr}$ (Asia) are found in the monsoonal runoff in response to the precessional forcing. In the model this is due to the following mechanism. For low summer insolation (precession maximum) precipitation is low and desert expands at the expense of grass, while for high insolation (precession minimum) precipitation is high and the tree fraction increases also reducing the grass fraction. This induces sub-Milankovitch variations in the grass fraction and associated variations in the water holding capacity of the soil. The runoff does not exhibit sub-Milankovitch variability when vegetation is kept fixed. High-latitude vegetation also exhibits sub-Milankovitch variability under both obliquity and precessional forcing. We thus hypothesize that sub-Milankovitch variability can occur due to the dynamic response of the vegetation. However, this mechanism should be further tested with more sophisticated climate/vegetation models.
\end{abstract}

\section{Introduction}

Evidence for climate variability on sub-Milankovitch timescales (here defined as $>2 \mathrm{kyr}$ (2000 years) and $<15 \mathrm{kyr}$ ) is often found in climate proxy records. These subMilankovitch signals are recorded in both marine and terrestrial data from different parts of the world, i.e. at high latitudes in the Atlantic Ocean (Hagelberg et al., 1994), in Spain (Rodríguez-Tovar and Pardo-Igúzquiza, 2003), in the

Correspondence to: E. Tuenter

(tuenter@knmi.nl)
Mediterranean Sea (Larrasoaña et al., 2003; Steenbrink et al., 2003; Becker et al., 2005), in the equatorial Pacific Ocean (Hagelberg et al., 1994), in marine sediments influenced by the strength of the African monsoon (Pokras and Mix, 1987; Hagelberg et al., 1994; McIntyre and Molfino, 1996) and by the strength of the Asian monsoon (Pestiaux et al., 1988; Naidu, 1998).

For most climatic parameters the presence of signals in the Milankovitch frequency band (i.e., eccentricity ( $100 \mathrm{kyr}$ and $400 \mathrm{kyr}$ ), precession ( $23 \mathrm{kyr}$ and $19 \mathrm{kyr}$ ) and obliquity (41 kyr)) can be explained by a linear response of the climate system to the orbital forcing (Imbrie et al., 1992; Jackson and Broccoli, 2003; Tuenter et al., 2005). In contrast, it is unlikely that the variability at sub-Milankovitch scales can be explained by a linear response because there is no known forcing at these timescales. The only exception is the double insolation maximum in the tropical regions in the course of a year, which is at the origin of $11 \mathrm{kyr}$ and $5.5 \mathrm{kyr}$ periods in equatorial insolation (Berger et al., 2006). In general, the occurrence of these sub-Milankovitch signals are explained by a nonlinear response of the climate to the orbital forcing. This nonlinear behaviour is expressed as sub-harmonics and combination tones of the primary orbital signals, as shown by Le Treut and Ghil (1983). They forced a simple nonlinear climatic oscillator with orbital frequencies and obtained periods near 10.5 and $5 \mathrm{kyr}$, with clusters of values around these periods.

A complicating factor in the study of sub-Milankovitch signals is the partitioning between the internal variability of the climate system and the possibly externally forced oscillations at sub-Milankovitch timescales (Le Treut and Ghil, 1983; Saltzman and Sutera, 1984). Climate models are a suitable tool to distinguish between the externally forced and internal variability of the climate system. Furthermore, experiments with climate models can also give some quantitative information about the amplitude of sub-Milankovitch variability. Unfortunately, studying sub-Milankovitch variability

Published by Copernicus GmbH on behalf of the European Geosciences Union. 


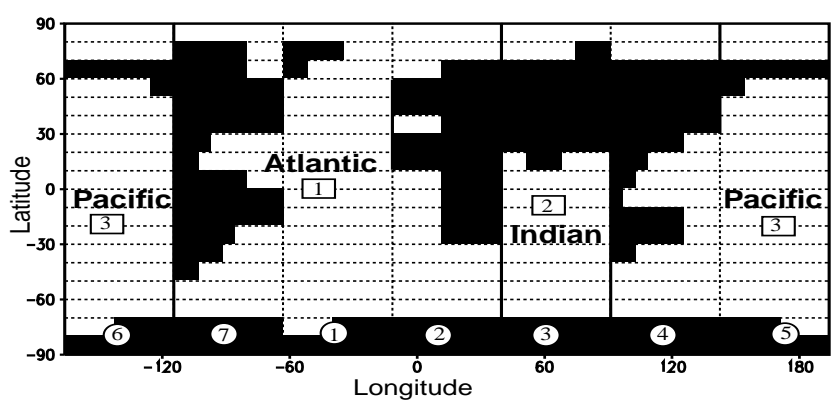

Fig. 1. Representation of the Earth's geography in CLIMBER-2.3. Dashed lines separate grid cells for the atmospheric component, with sector numbers given in circles. Solid lines separate the three ocean sectors, numbered in squares (the latitudinal resolution for the ocean is $2.5^{\circ}$ ). The black areas indicate the relative fraction of land within each atmospheric grid cell, placed arbitrarily within an atmospheric cell.

with models requires long transient simulations leading to high computational costs. For this reason model studies concerning sub-Milankovitch variability are not very numerous and they have only been done with relatively simple models. Using a two-dimensional EBM (Energy Balance Model), Short et al. (1991) found climatic variability at timescales of 10-12 kyr for the maximum summer temperature over equatorial Africa (see also Crowley et al., 1992). Short et al. (1991) explained this by the twice overhead passage of the sun for equatorial regions. This causes a movement of the maximum temperature from spring to fall (and vice versa) and a signal at half of the precession period. The EBM of Short et al. (1991) did not include a hydrological cycle, but they speculated that the summer monsoon would also exhibit a period of $10-12 \mathrm{kyr}$ assuming that the maximum summer temperature gives an indication for the local moisture availability. Transient simulations were also done with an Earth system model of Intermediate Complexity (EMIC, Claussen et al. (2002)) which includes a hydrological cycle (Tuenter et al., 2005). At $15^{\circ} \mathrm{N}$ during maximum precession (i.e., when winter solstice occurs in perihelion) two maxima for the temperature were found in these experiments (one in April and a weaker one in November). However, during minimum precession (summer solstice in perihelion) only one maximum was found (in July). Furthermore, both during minimum and maximum precession there is only one precipitation maximum (in July). This illustrates that the maximum summer temperature and precipitation are not linearly related. As an associated result, Tuenter et al. (2005) did not find sub-Milankovitch signals in the monsoonal precipitation. However, they found some variability at subMilankovitch timescales in the annual runoff from the continental area affected by the African and Asian summer monsoon.
In this paper the sub-Milankovitch variability as seen in Tuenter et al. (2005) is studied in more detail. Focus is on the African and Asian monsoon at Northern Hemisphere low latitudes, as most sediment records showing sub-Milankovitch variability seem to be influenced by the strength of the monsoon (Pokras and Mix, 1987; Pestiaux et al., 1988; Hagelberg et al., 1994; McIntyre and Molfino, 1996; Larrasoaña et al., 2003). Sub-Milankovitch signals at Northern Hemisphere high and mid-latitudes will also be briefly described. The model and experimental set-up are described in Sect. 2. In Sect. 3 the model results are discussed, while in Sect. 4 the study will be summarized and discussed.

\section{The model and experimental set-up}

We use the coupled model of intermediate complexity CLIMBER-2.3 (for CLIMate and BiosphERe, version 2, Petoukhov et al., 2000). The model consists of an atmosphere model, an ocean/sea-ice model and a land/vegetation model. This version of the model contains no ice sheet model. No flux adjustments are used.

The atmospheric model is a 2.5-dimensional statisticaldynamical model with a resolution of $10^{\circ}$ in latitude and approximately $51^{\circ}$ in longitude (Fig. 1). The model does not resolve synoptic timescales but uses statistical characteristics associated with ensemble-means of the system. The vertical structure of temperature and humidity is prescribed. These vertical profiles are used for the computation of the 3-dimensional fields of the atmospheric circulation and the radiative fluxes. The vertical resolution for the circulation, temperature and humidity is 10 levels and for the long-wave radiation 16 levels. The time step is one day.

The terrestrial vegetation model is VECODE (VEgetation COntinuous DEscription, Brovkin et al., 1997). The model computes the fractions of trees and desert in each atmospheric grid cell, while the grass fraction is a dummy variable. Both tree and desert fractions are functions of the accumulation of daily positive degrees during the year, also called growing day degree (GDD), and the annual precipitation. In a cold climate, temperature is the major limiting factor to tree growth and below a threshold $(\mathrm{GDD}<1000)$ the tree fraction declines rapidly to zero. In a warm climate the annual precipitation is the main limiting factor to tree growth. We refer to Brovkin et al. (1997) for an extensive description of the computation of the tree fraction. There are two types of deserts: cold and warm ones. The cold deserts (e.g. over Antarctica and Greenland) are driven by temperature. If GDD is less than 100 the gridbox is fully covered by desert, while the desert fraction linearly decreases from one to zero between GDD 100 and 800. Warm deserts can only form if GDD is higher than 1800 , driven by the lack of (annual) precipitation. The fraction of grass is determined as the remaining fraction of the grid cell, after the computation of the tree fraction and the desert fraction. The computed vegetation changes affect 
the land-surface albedo and the hydrological cycle. The time step of VECODE is one year.

The atmosphere/surface interface is based on the Biosphere-Atmosphere Transfer Scheme (BATS) described in Dickinson et al. (1986). The land model consists of a two layer soil model. The water balance in the upper soil layer is determined by the sum of precipitation, evaporation and transpiration, melting of snow, runoff and drainage. Surface runoff depends on relative soil moisture of the upper soil layer and precipitation (Petoukhov et al., 2000). Vegetation also influences the runoff due to the different values of soil water holding capacity of each vegetation type, i.e. the ability of soil to store water which is not available for runoff. The soil water holding capacity is highest for areas covered with trees, lowest for areas covered with desert and intermediate for grass covered areas. The total runoff of a gridbox is the sum of the runoff from the fractions covered with trees, grass and desert in this gridbox.

The ocean model is based on the model of Stocker et al. (1992) and describes the zonally averaged temperature, salinity and velocity for three separate basins (Atlantic, Indian and Pacific oceans, Fig. 1). The three basins are connected by the Southern Ocean through which mass, heat and salt are exchanged. The latitudinal resolution is $2.5^{\circ}$ and there are 20 unequally spaced depth levels. The time step is 5 days. The ocean model includes a thermodynamic seaice model that computes the sea-ice fraction and thickness for each grid box, with a simple treatment of advection and diffusion of sea-ice.

Results of CLIMBER-2 compare favorably with data of the present-day climate (Ganopolski et al., 1998b; Petoukhov et al., 2000). Results of sensitivity experiments (like changes in $\mathrm{CO}_{2}$, vegetation cover and solar irradiance) performed with CLIMBER-2 agree reasonably well with results of more comprehensive models (Ganopolski et al., 2001). The model is successful in simulating cold climates (Ganopolski et al., 1998b), while Ganopolski et al. (1998a) and Kubatzki et al. (2000) have shown that the model is also capable of simulating warm periods like the mid-Holocene and the last interglacial (6 kyr and $125 \mathrm{kyr}$ Before Present (BP)), respectively. The model has been used for transient simulations of the (African) monsoon with good agreement with paleoclimatic data (Claussen et al., 1999). Concerning the vegetation component, results with a high-resolution version of VECODE forced by a high-resolution atmosphere model agree reasonably well with other vegetation models and observations (Cramer et al., 2001).

With CLIMBER-2 we performed 3 different transient simulations for the interval from 280 to $150 \mathrm{kyr} \mathrm{BP}$. One to examine the climatic response to the precession forcing alone, one to the obliquity forcing and one to the combined forcing. The orbital parameters used in this study were computed with the method described in Berger (1978). For the precession signal $(\mathrm{P})$ the eccentricity and precession are shown in Fig. 2 while obliquity (or tilt) was fixed at a minimum value (22.08

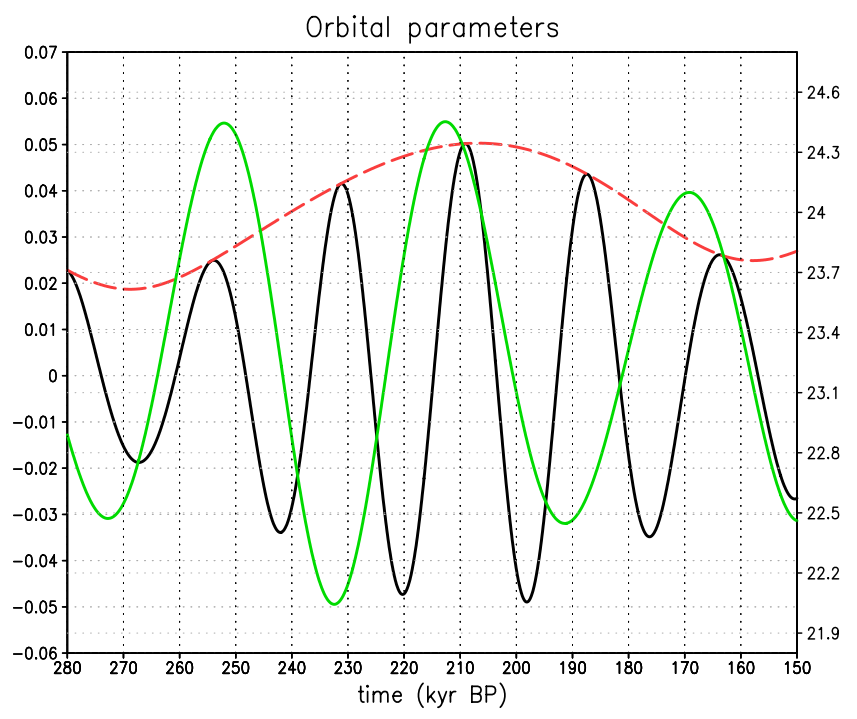

Fig. 2. Orbital parameters for the period 280-150 kyr BP: Eccentricity (red, dashed line), the precession parameter (solid black line) and obliquity (solid green line). The left vertical axis displays the values for eccentricity and the precession parameter. The right axis shows the values for obliquity (in degrees). The horizontal axis displays time (in 1000 years Before Present).

degrees), see also Table 1. The precession index is defined as $e \sin (\pi+\tilde{\omega})$ with $e$ being the eccentricity of the Earth's orbit and $\tilde{\omega}$ the angle between the vernal equinox and perihelion (measured counter clockwise). We will use the terms 'minimum' and 'maximum' precession referring to the minimum and maximum values of $e \sin (\pi+\tilde{\omega})$, respectively. We used the minimum obliquity of the epoch for the precession simulation because the same value was already used in equilibrium experiments (Tuenter et al., 2003). In that paper it was shown that the climate response to the precession forcing does not depend on the prevailing obliquity.

The climatic response to the obliquity forcing (experiments $\mathrm{T}$ and TV) was studied by varying the tilt and using a circular Earth orbit (i.e., eccentricity $=0$ ), see Fig. 2 and Table 1. In experiments T and TV a circular Earth orbit is used to exclude any influence of precession $(e \sin (\pi+\tilde{\omega})=0$ for each $\tilde{\omega})$. It is useful to eliminate the precession signal because in equilibrium experiments it was found that the response of the climate to the obliquity forcing could depend on the prevailing precession. The third simulation combines the precession and obliquity signal (PT, Table 1) by varying both obliquity and the precession parameter.

The 280-150 kyr BP interval was selected because it contains an eccentricity cycle with a large amplitude (although it is not the most extreme eccentricity cycle of the last 1 million years) and the most extreme obliquity oscillations of the last 1 million years. 
Table 1. Orbital configuration and vegetation used for the 6 transient experiments as described in Tuenter et al. (2005). P is the precession experiment with fixed vegetation, $\mathrm{T}$ is the obliquity (Tilt) experiment with fixed vegetation and PT is the combined precession and obliquity experiment with fixed vegetation. PV, TV, and PTV are the precession, obliquity and combined experiments with interactive vegetation, respectively. PD stands for Present-Day. The tilt is defined as the angle between the ecliptic and the equator, $e$ is the eccentricity of the orbit of the Earth and $\tilde{\omega}$ is the angle between the vernal equinox and perihelion (measured counter clockwise).

\begin{tabular}{lcccc}
\hline Experiment & Tilt (degrees) & Precession $(e \sin (\pi+\tilde{\omega}))$ & Eccentricity & Vegetation \\
\hline P & Fixed (22.08) & Variable (Fig. 2) & Variable (Fig. 2) & Fixed (PD) \\
T & Variable (Fig. 2) & Fixed (0.0) & Fixed (0.0) & Fixed (PD) \\
PT & Variable (Fig. 2) & Variable (Fig. 2) & Variable (Fig. 2) & Fixed (PD) \\
PV & Fixed (22.08) & Variable (Fig. 2) & Variable (Fig. 2) & Interactive \\
TV & Variable (Fig. 2) & Fixed (0.0) & Fixed (0.0) & Interactive \\
PTV & Variable (Fig. 2) & Variable (Fig. 2) & Variable (Fig. 2) & Interactive \\
\hline
\end{tabular}

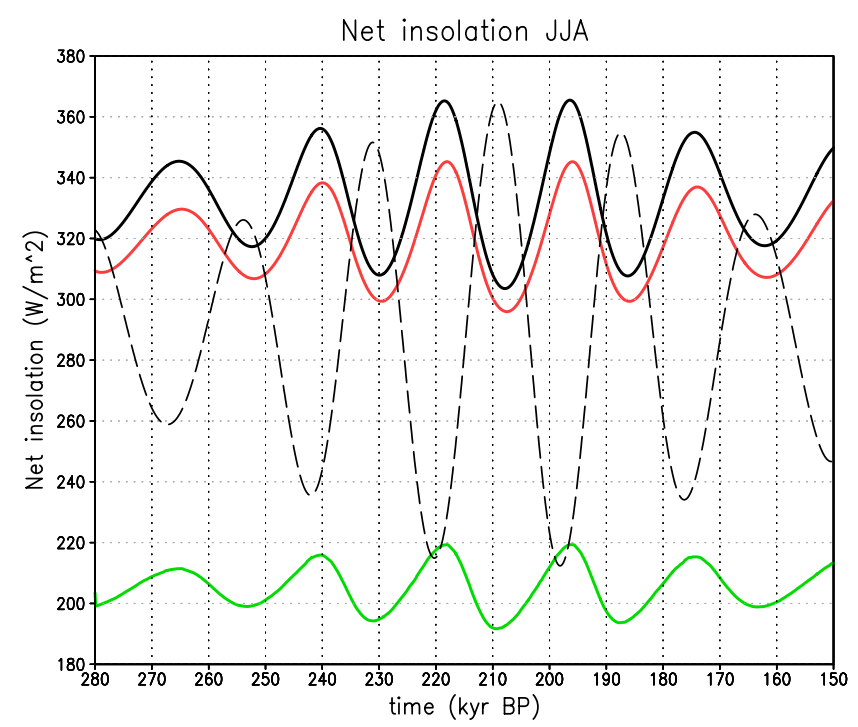

Fig. 3. Zonally averaged net incoming insolation at the top of the atmosphere averaged over June-August for $15^{\circ} \mathrm{N}$ (solid black line), $45^{\circ} \mathrm{N}$ (red line) and $75^{\circ} \mathrm{N}$ (green line) for experiment $\mathrm{P}$ (Table 1). Also shown is the precession parameter (dashed black line, arbitrary scale). The horizontal axis displays time (in 1000 years Before Present).

All experiments described above have been carried out with the coupled atmosphere-ocean model and with the atmosphere-ocean-vegetation model. In the simulations with the atmosphere-ocean model the vegetation was prescribed according to observed present-day coverage and was kept constant during the simulations. The results of the simulations with the atmosphere-ocean-vegetation model will be denoted as PV, TV and PTV for the precession, obliquity and combined simulations, respectively (Table 1).

For all simulations the boundary conditions like orography, land-sea configuration, ice sheets and concentration of trace gasses were kept constant. For the initial state presentday conditions were used for all simulations. The results will be shown as averages over 100 years as the Milankovitch and sub-Milankovitch periods of interest here are much larger than 100 years.

The precession signal in the Northern Hemisphere summer insolation consists of increased insolation during minimum precession with respect to maximum precession (Fig. 3) while in boreal winter the insolation is weaker during minimum precession compared to maximum precession (not shown). At high northern latitudes changes in obliquity cause stronger insolation during boreal summer and weaker insolation during winter going from minimum to maximum obliquity. At low latitudes the obliquity signal in the insolation is very small (not shown).

\section{Results}

\subsection{The African and Asian monsoon}

In Tuenter et al. (2005) the African and Asian monsoon were combined because at Milankovitch timescales they behave similarly. However, it will become clear that at subMilankovitch timescales they behave differently and for that reason they will be discussed separately. If we discuss characteristics (e.g., runoff, precipitation) for the "African" and "Asian" monsoon we refer to the gridbox located in atmospheric sector $2\left(10^{\circ} \mathrm{N}-20^{\circ} \mathrm{N}\right)$ and atmospheric sector 3 $\left(20^{\circ} \mathrm{N}-30^{\circ} \mathrm{N}\right)$, respectively (Fig. 1). At low latitudes the precession signal is much stronger than the obliquity signal, although the obliquity signal is not negligible (Tuenter et al., 2005). Consequently, to a large extent experiments PT and PTV show the same characteristics as experiments $\mathrm{P}$ and PV, respectively. Therefore we will focus on the results of experiments $\mathrm{P}$ and $\mathrm{PV}$.

The monsoonal precipitation is stronger during minimum precession compared to maximum precession (Figs. $4 \mathrm{a}$ 
and 5a) which can mainly be attributed to the enhanced differential heating between land and ocean due to the stronger insolation in boreal summer (Fig. 3). Including an interactive vegetation model leads to a stronger response for both the African and the Asian monsoon (Figs. 4a and 5a). This can be explained by a stronger hydrological cycle and larger albedo differences induced by vegetation (Broström et al., 1998; Doherty et al., 2000; Tuenter et al., 2005).

Qualitatively, the vegetation response to the precession forcing is similar for the African and Asian monsoon (Figs. 4b and 5b). During precession minima the tree fraction increases sharply, while the desert fraction reduces to zero. During precession maxima desert expands within the gridcell, while the tree fraction falls back. This can be attributed to the stronger monsoonal rainfall during precession minima compared to precession maxima. Because the grass fraction depends on the tree and desert fraction, the alternating presence of trees and desert causes a decrease of the grass fraction both during precession minima and maxima (Figs. 4b and 5b).

Spectra for the desert and grass fractions are shown in Fig. 6. The power spectra shown in this study were obtained by using the CLEAN transformation of Roberts et al. (1987). For the determination of significance levels associated with the frequency spectra of the CLEAN algorithm, we applied a Monte Carlo based method developed by Heslop and Dekkers (2002), which was run as a MATLAB routine. The CLEAN spectra were determined by adding $10 \%$ red noise (i.e., control parameter $=0.1$ ), a clean/gain factor of 0.1, 500 CLEAN Iterations and 1000 simulation iterations. We refer to Roberts et al. (1987) and Heslop and Dekkers (2002) for an extensive description including advantages and drawbacks of the CLEAN transformation.

In Fig. 6 it can be seen that there are additional periods of about $10 \mathrm{kyr}$ in the spectra, apart from the precession period. In case of the grass fraction this period is visible by eye in the timeseries (Fig. 4b), while in case of the desert (and tree) fractions this period seems to be an artifact of the spectral analysis caused by so-called "clipping" (Hagelberg et al., 1994). This is introduced by the fact that the vegetation fractions cannot be negative. The sharp transitions caused by the non-negativity introduce energy into the power spectrum at the sub-harmonic frequencies of precession (Fig. 6). Clearly, these sub-harmonics are not present in the data but they are artificial periods caused by clipping (Hagelberg et al., 1994). In the real world clipping can also occur due to the fact that climate variables cannot become smaller or larger than a certain threshold. As for model data, clipping in the real world can also introduce artifical sub-Milankovitch periods due to an artifact of the spectral analysis (Hagelberg et al., 1994).

The amplitude of the vegetation response to precession is larger for the Asian monsoon than for the African monsoon, especially during precession maxima (Figs. 4b and 5b). When eccentricity is high, the entire Asian monsoon region is completely covered by desert during precession maxima.
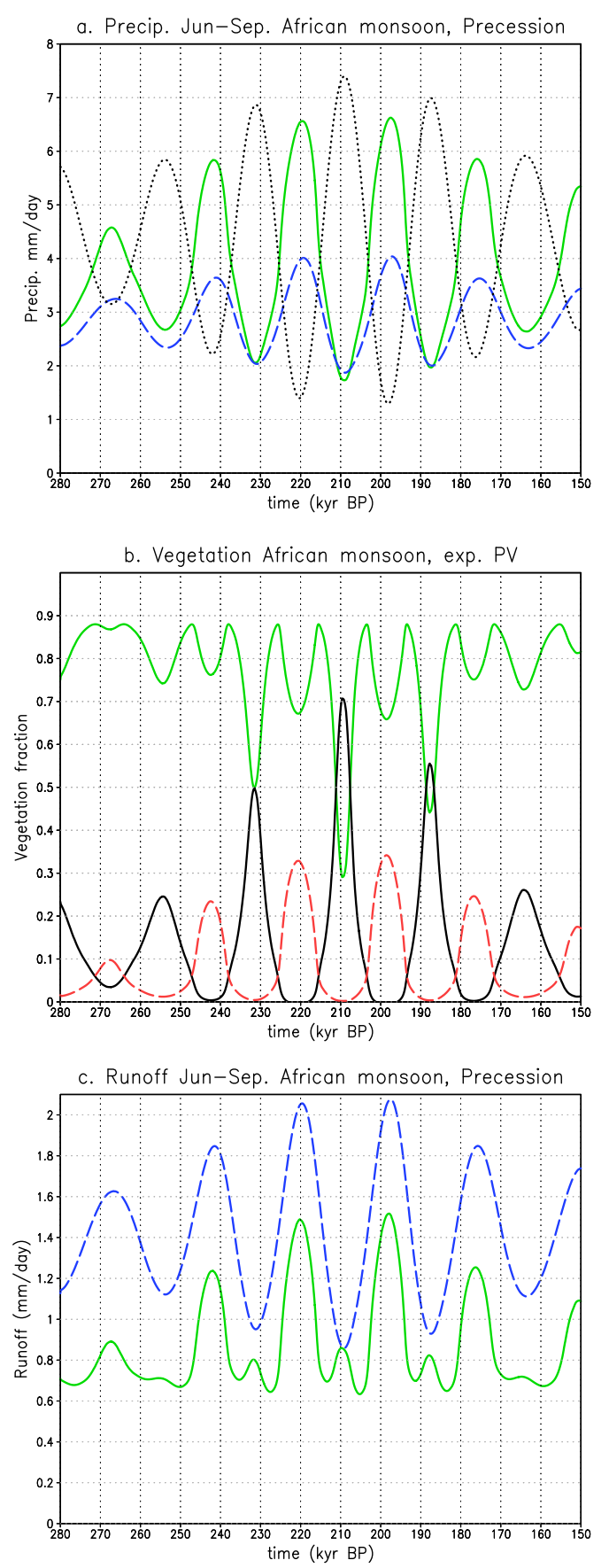

Fig. 4. Climate variables for the African monsoon: (a) Precipitation (in $\mathrm{mm} /$ day) averaged over June-September for experiment $\mathrm{P}$ (dashed blue line) and experiment PV (green solid line) together with the precession parameter (dotted black line, arbitrary scale). (b) Annual grass fraction (green solid line), annual desert fraction (black solid line) and annual tree fraction (dashed red line) for experiment PV and (c) Runoff (in $\mathrm{mm} /$ day) averaged over JuneSeptember for experiment $\mathrm{P}$ (dashed blue line) and experiment PV (green solid line). The horizontal axes denote time (in 1000 years Before Present). 

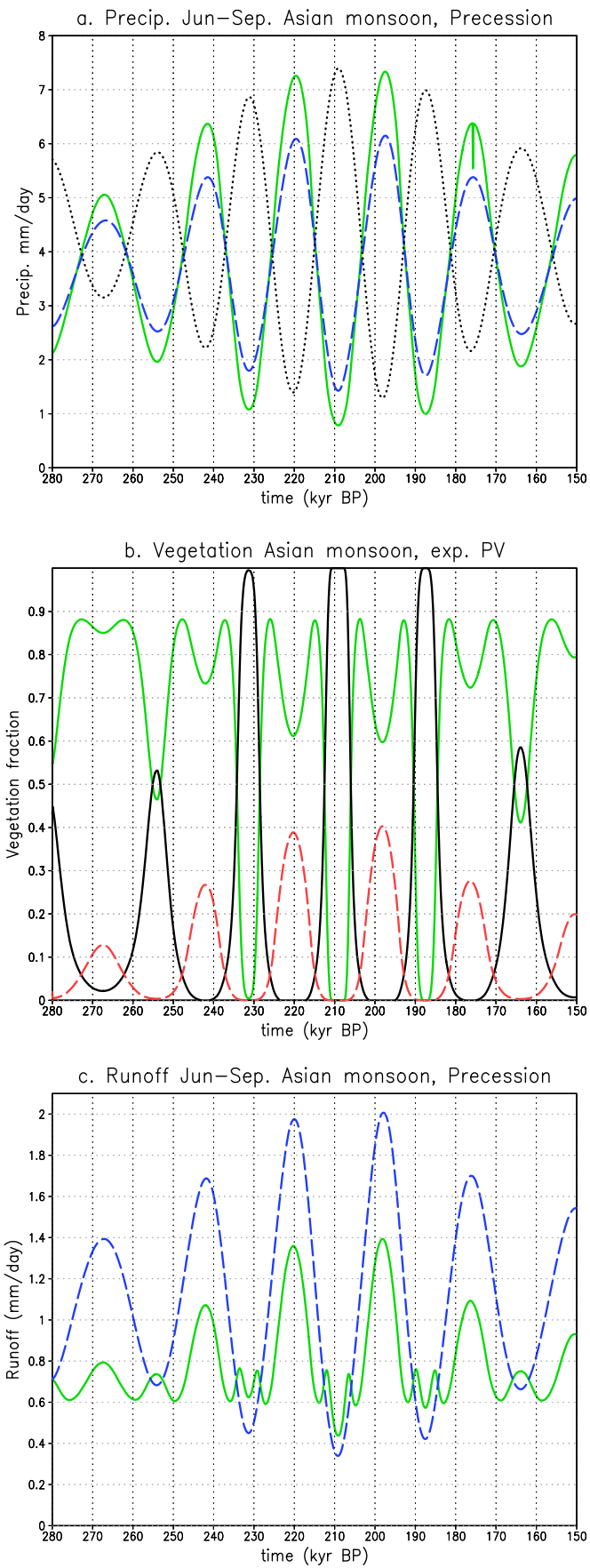

Fig. 5. Similar as for Fig. 4 but now for the Asian monsoon.

The larger desert fraction for the Asian monsoon compared to the African monsoon can be explained by the smaller amount of precipitation during precession maxima (Figs. $4 \mathrm{a}$ and $5 \mathrm{a}$ ) and by the lower annual surface air temperature (not shown) for the Asian monsoon compared to the African monsoon.
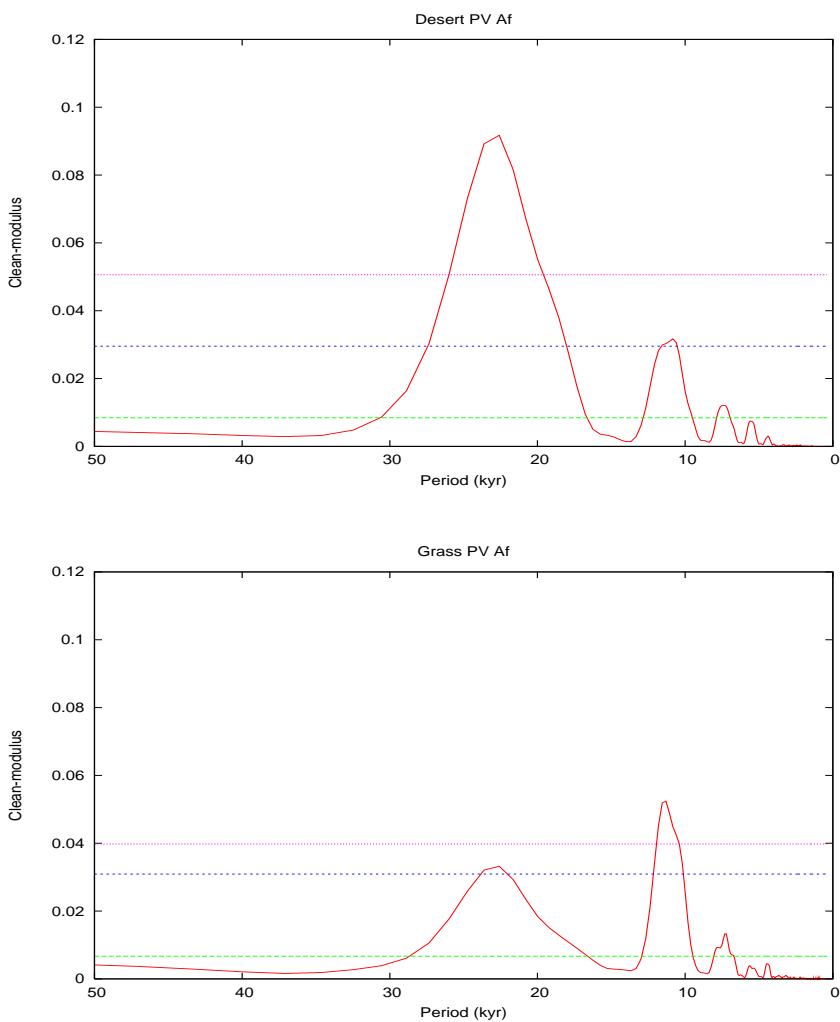

Fig. 6. Power spectrum of results from experiment PV for the desert fraction (upper panel) and the grass fraction (lower panel) for the African monsoon. The pink, blue and green line indicate the $99.5 \%, 99 \%$ and $95 \%$ confidence level, respectively. The statistical significance for the grass fraction is computed without taking its dependency on the tree and desert fractions into account. The sub-harmonics frequencies of precession in the desert fraction are artificial frequencies as they are caused by clipping. The frequencies computed for the grass fraction are not artificial because there is no clipping (see text for more information).

During precession minima the runoff from the the African and Asian monsoon increases due to the increased precipitation in experiments $\mathrm{P}$ and PV (Figs. 4c and 5c). In experiment $\mathrm{P}$ the runoff is at a minimum during precession maxima, which is in agreement with the minimum in precipitation. This results in a power spectrum with the precession period, but no other periods, for experiment $\mathrm{P}$ (not shown). In experiment PV the runoff from the area affected by the African monsoon is at a (secondary) maximum during precession maxima (Fig. 4c). These secondary maxima cause an additional $10 \mathrm{kyr}$ period apart from the precession period (Fig. 7). In case of the Asian monsoon the runoff is also at a maximum during weak precession maxima in experiment PV (i.e., around 255 and 163 kyr BP, Fig. 5c). However, during strong precession maxima the Asian monsoonal runoff is at a minimum and the maximum occurs several thousands of years before and after this minimum (Fig. 5c). This leads to a 
weak (but significant) $\sim 5 \mathrm{kyr}$ period apart from the $\sim 10 \mathrm{kyr}$ period (and the precessional period) in the Asian runoff signal (Fig. 7).

To explain the mechanism underlying the occurrence of the sub-Milankovitch variability in the runoff, we will focus on the period with the strongest minimum and maximum precession, i.e., 217-190 kyr BP. The periodic behaviour of the runoff is similar in all monsoon months but the largest amplitude occurs in July. For this reason we will only show the results for July.

Starting with a minimum precession (at $220 \mathrm{kyr}$ BP, Fig. 2) the total runoff from the African monsoon decreases due to a decrease in the precipitation (Figs. 8a, c). Due to the decrease in the precipitation the desert area grows at the expense of the grass fraction (Fig. 8b). After some time this causes an increase of the runoff (despite the decreasing precipitation), because bare soil can hold less water than grass. As a result at maximum precession (209 kyr BP) a secondary maximum in the runoff occurs concurrent with the maximum extent of the desert (Figs. 8b, c). After maximum precession the precipitation increases causing a decrease in the desert fraction and an increase in the grass fraction. This results in a decrease in the runoff because the expanding grass fraction retains more ground water. However, when precipitation further increases the runoff from the grass increases and together with the runoff from the trees this leads to a runoff maximum around minimum precession at $198 \mathrm{kyr} \mathrm{BP}$ (Fig. 8c).

A similar mechanism as described above causes the subMilankovitch signals in the runoff associated with the Asian monsoon. Again, starting with a minimum precession the Asian runoff decreases due to a decrease in the precipitation (Figs. 9a, c). At the same time the desert area grows at the expense of the grass fraction (Fig. 9b). This, again, causes an increase of the runoff, because bare soil can hold less water than grass. A difference compared to the African monsoon is that the desert fraction reaches its maximum while the precipitation is still decreasing (Figs. 9a, b). The ongoing decrease of precipitation then leads to a (second) runoff minimum at around $210 \mathrm{kyr} \mathrm{BP}$, which is absent in case of the African monsoon (cf. Figs. $8 \mathrm{c}$ and 9c). After $\sim 210 \mathrm{kyr}$ $\mathrm{BP}$ the runoff increases together with the increasing precipitation until around $206.5 \mathrm{kyr}$ BP (Figs. 9a, c). At that time the grass fraction starts to increase, leading to a decrease of the runoff due to the stronger water holding capability of grass compared to desert. This results in a third runoff minimum at around $205 \mathrm{kyr}$ BP (Fig. 9c). Finally, due to the still increasing precipitation the runoff increases leading to a maximum around minimum precession (198 kyr BP).

The variations in the runoff at sub-Milankovitch timescales induce small sub-Milankovitch signals in the annual salinity of the ocean gridboxes in which the monsoonal runoff is dumped. This is particularly clear in smaller basins like the Mediterranean Sea (sector $2 ; 30^{\circ} \mathrm{N}-$ $35^{\circ} \mathrm{N}$, Fig. 1) and the northern Indian Ocean (sector 3; $10^{\circ} \mathrm{N}-20^{\circ} \mathrm{N}$, Fig. 1) (not shown). The amplitude of the

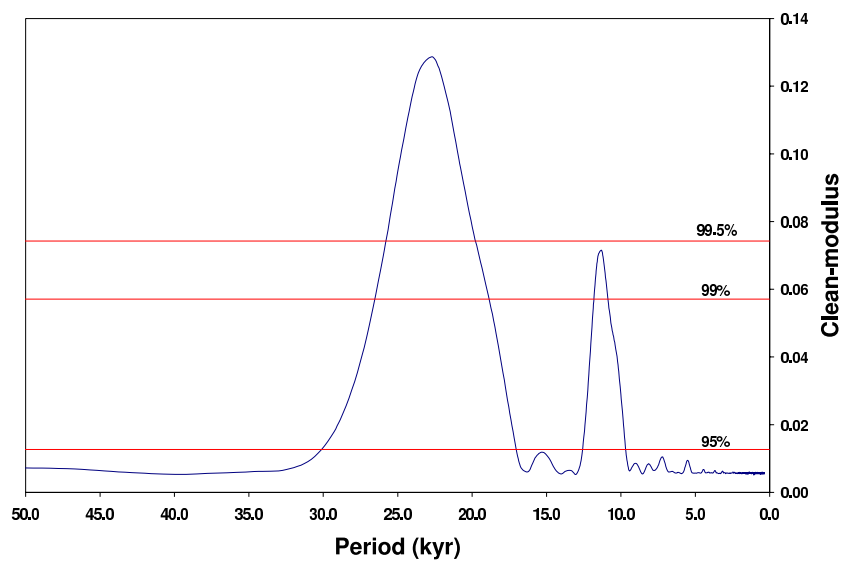

Run PV - As (JJAS)

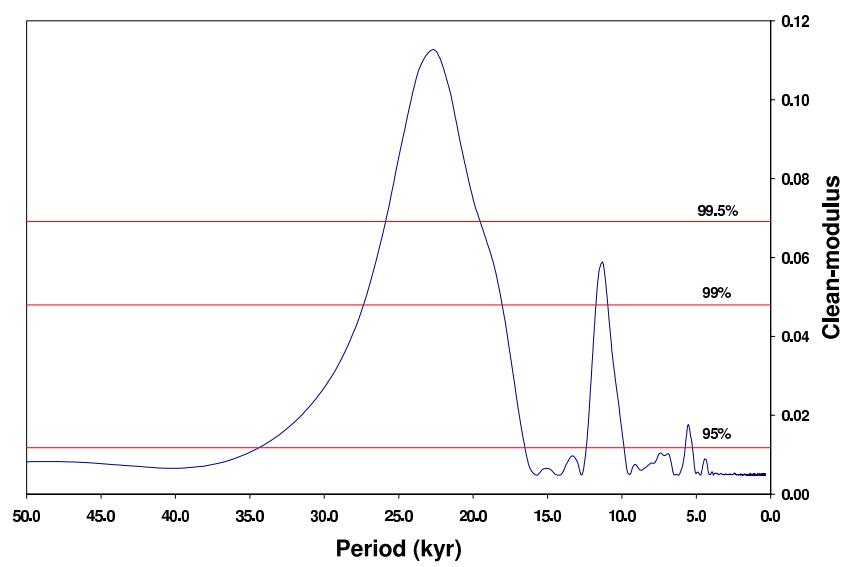

Fig. 7. Power spectra of results from experiment PV for the JuneSeptember runoff for the African monsoon (upper panel) and for the Asian monsoon (lower panel). The horizontal red lines indicate the confidence levels.

sub-Milankovitch variability in the annual salinity is about $10 \%$ of the precessional variability. No sub-Milankovitch signals are found in the ocean circulation.

As in experiment $\mathrm{PV}$, in the obliquity experiment TV there are no sub-Milankovitch variations in the monsoonal precipitation. There are similar sub-Milankovitch signals in the vegetation fractions for the areas affected by the African and the Asian monsoon as in experiment PV, i.e., the grass fraction varies due to alternating variations in the desert fraction and in the tree fraction (not shown). This leads to a period of about $20 \mathrm{kyr}$ apart from the period of $41 \mathrm{kyr}$. However, the amplitudes of the variations in the grass fractions are small (about 0.05 for and 0.1 for the African and Asian monsoon, respectively) in experiment TV. This is too small to induce sub-Milankovitch variability in the runoff.

The results of the combined experiment PTV are almost linear combinations of the results of experiments PV and TV 

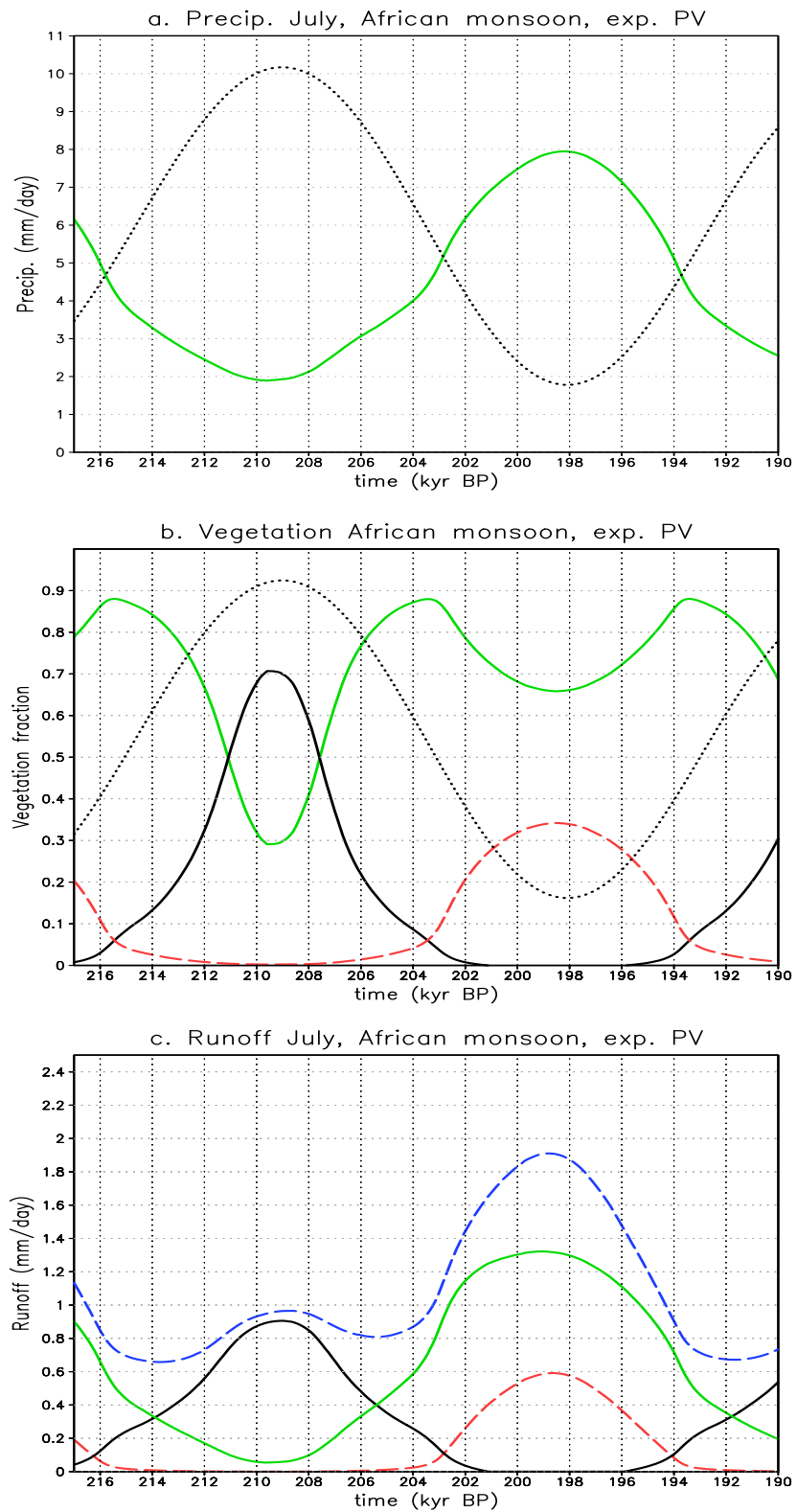

Fig. 8. Climate variables for the African monsoon from experiment PV. (a) Precipitation (in mm/day) for July (solid green line) together with the precession parameter (dotted black line, arbitrary scale), (b) Annual grass fraction (solid green line), annual desert fraction (black solid line) and annual tree fraction (dashed red line) and (c) Total runoff (dashed blue line), runoff originating from the grass area (solid green line), from the tree area (dashed red line) and from the desert area (solid black line), all for July. The horizontal axes denote time (in 1000 years Before Present).

(Tuenter et al., 2005). This implies that the vegetation and runoff for the African and Asian monsoon areas in experiment PTV are governed by precession rather than obliquity. This leads to similar sub-Milankovitch variability in the veg-
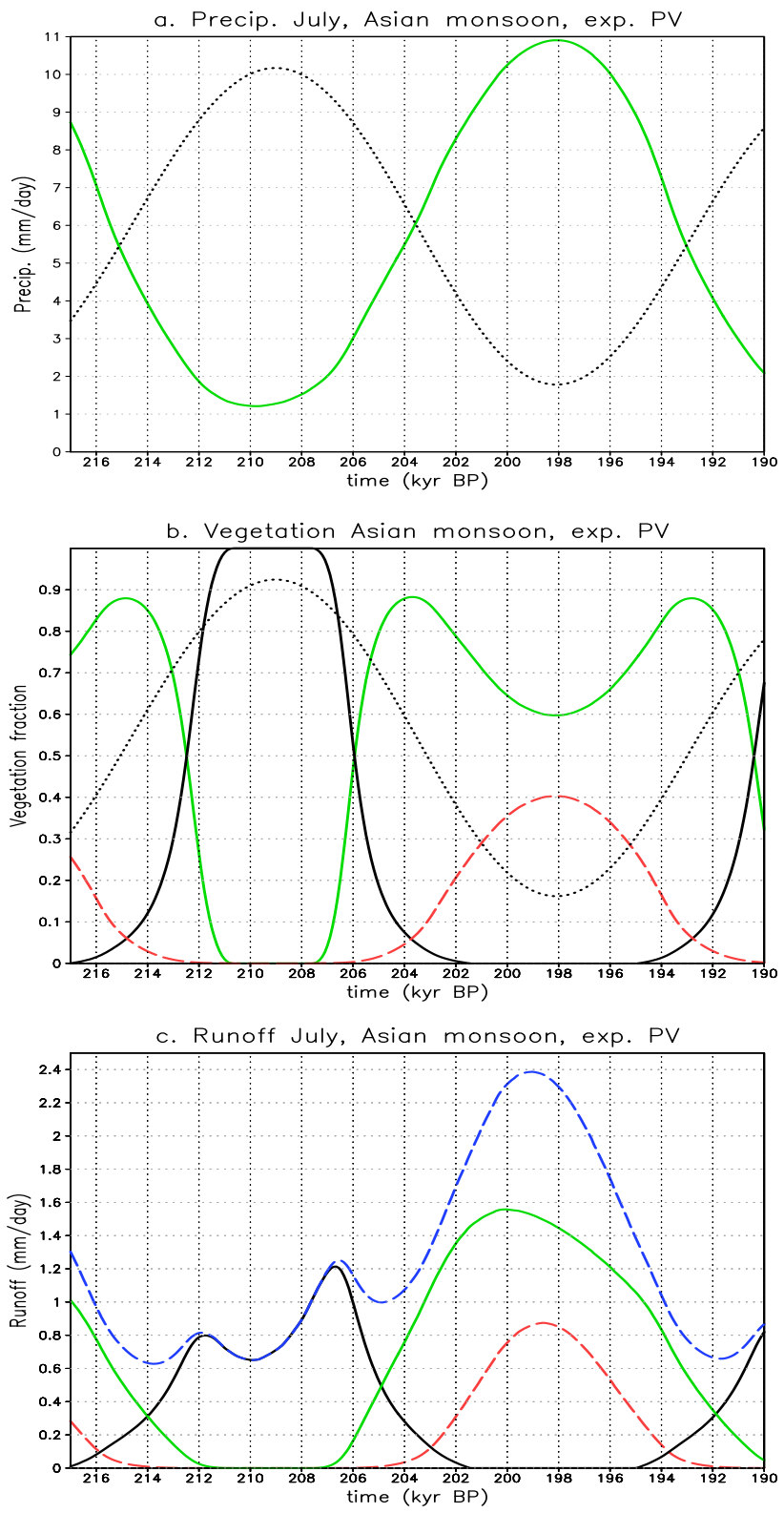

Fig. 9. Similar as for Fig. 8 but now for the Asian monsoon.

etation and runoff in experiment PTV as shown in Figs. 4 and 5 .

\subsection{Sub-Milankovitch in other regions}

Similar sub-Milankovitch variability in the vegetation as shown in Figs. $4 \mathrm{~b}$ and $5 \mathrm{~b}$ also exists for high- and midlatitudinal regions for both obliquity and precession. Some examples are the northern Asian continent (Figs. 10a, b), northern Canada (atmospheric sector 7, $60^{\circ} \mathrm{N}-70^{\circ} \mathrm{N}$, not shown) in experiments PV and TV and the East Asian region (atmospheric sector $4,30^{\circ} \mathrm{N}-40^{\circ} \mathrm{N}$ ) in experiment $\mathrm{PV}$ 
(not shown). In contrast to low latitudes the main driving force for these sub-Milankovitch signals is not precipitation but surface air temperature (SAT). When the boreal summer SAT is high due to strong insolation (i.e., during precession minima (Fig. 3) and obliquity maxima) tree fraction expands while during time intervals with low summer SAT (precession maxima and obliquity minima) the desert fraction expands (Figs. 10a, b). As for low latitudes, this alternating presence of trees and desert causes a decrease of the grass fraction both during precession minima and maxima (Fig. 10b) and during obliquity minima and maxima (Fig. 10a). For obliquity this introduces a sub-Milankovitch period of about $20 \mathrm{kyr}$ for the grass fraction (not shown) which is very close to the primary orbital periods of precession (19 and $23 \mathrm{kyr}$ ).

An example for which sub-Milankovitch variability in the vegetation does not only introduce sub-Milankovitch variability in the runoff, but also in the SAT, is given for the Sahara (Fig. 10c). The SAT minima during precession minima (e.g. at $220 \mathrm{kyr} \mathrm{BP}$ ) are caused by the low insolation during boreal winter. The sudden increase of SAT around $225 \mathrm{kyr}$ $\mathrm{BP}$ is caused by the expansion of the grass fraction. Due to the stronger summer insolation during minimum precession (Fig. 3) the monsoonal precipitation increases causing an increase of the grass fraction from zero to about 0.85 at the expense of the desert fraction (not shown). This results in a lower surface albedo (i.e. a decrease of 0.15) due to the lower albedo of grass compared to desert. This, in turn, leads to higher SAT (Fig. 10c). The sudden decrease of SAT some thousands of years after precession minima (e.g. at $218 \mathrm{kyr}$ BP, see Fig. 10c) can be explained by a similar reasoning. The precipitation decrease in summer leads to a larger desert fraction and a smaller area covered with grass. This results in a higher surface albedo and a sudden decrease of the SAT (Fig. 10c).

Sub-Milankovitch variability in other climatic parameters (both in the ocean and atmosphere) are also found. However, this variability is either very small or it is caused by clipping. This clipping can especially be seen for climate variables which cannot become negative like snow fractions and sea-ice fractions (not shown). As explained above, this clipping introduces artificial sub-Milankovitch variability at the harmonic frequencies of precession and obliquity (Hagelberg et al., 1994). Furthermore, it also transports energy into the power spectrum at the modulating period of precession, i.e. eccentricity (Crowley et al., 1992).

\section{Summary and discussion}

In this study, we investigated whether climate variability at sub-Milankovitch periods (between 2 and $15 \mathrm{kyr}$ ) can be simulated in long $(130 \mathrm{kyr})$ experiments with an EMIC (CLIMBER-2). Our approach was to study the climate response to the separate obliquity and precession forcing. Fur-
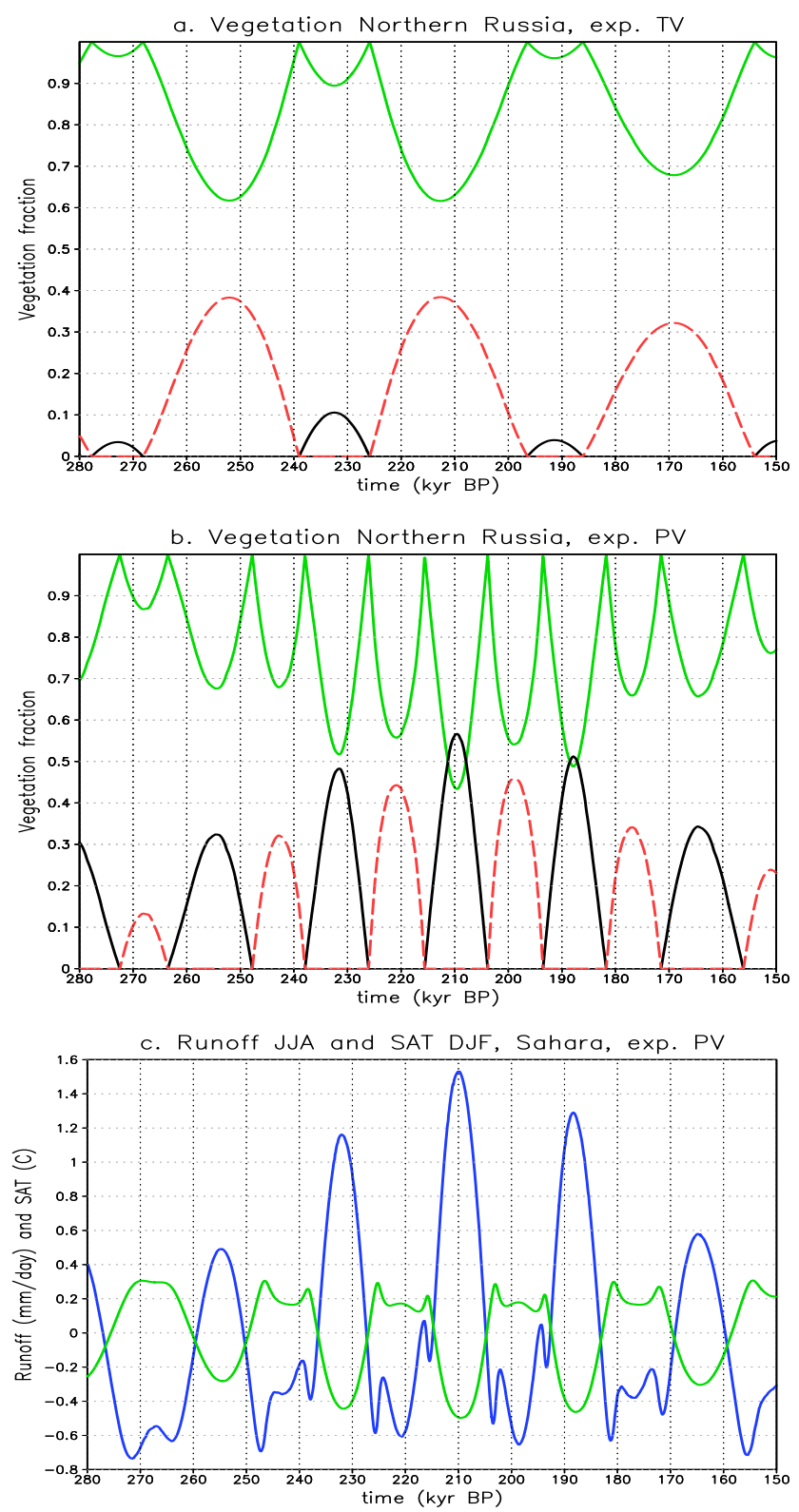

Fig. 10. Annual grass fraction (solid green line), annual tree fraction (dashed red line) and the annual desert fraction (black solid line) for northern Russia (atmospheric sector 3, $70^{\circ} \mathrm{N}-80^{\circ} \mathrm{N}$ ) for experiment PV (a) and experiment TV (b). (c) Anomalous runoff averaged over June-July-August (solid green line) and anomalous surface air temperature averaged over December-January-February (solid blue line) for the Sahara (atmospheric sector 2, $20^{\circ} \mathrm{N}-30^{\circ} \mathrm{N}$ ) and for experiment PV. The anomalies are computed with respect to the values averaged over the whole time interval (280-150 kyr BP). The horizontal axes denote time (in 1000 years Before Present).

thermore, we also performed the simulations with and without an interactive vegetation model. Focus is on the regions affected by the African and Asian monsoon. 
No sub-Milankovitch variability was found in the monsoon precipitation itself in any of the simulations. However, in the precession experiment with interactive vegetation sub-Milankovitch variability was found in the vegetation and runoff in the monsoon regions. In the run with constant vegetation no sub-Milankovitch periods were found in the monsoonal runoff. The mechanism for sub-Milankovitch signals in the vegetation is similar for the Asian and African monsoon regions: the grass fraction decreases due to the increase of both the desert fraction (during maximum precession) and the tree fraction (during minimum precession). This introduces a period of about $10 \mathrm{kyr}$ for the grass fraction and an associated signal in the monsoonal runoff, caused by the different water holding capacities of trees, grass and desert. Runoff from the Asian monsoon area shows a secondary subMilankovitch period ( $\sim 5 \mathrm{kyr})$, due to differences in the amplitudes of the vegetation signal.

The mechanism for sub-Milankovitch variability in lowlatitude vegetation cover can be also found at high and midlatitudes. At high latitudes the obliquity forcing can also lead to variations at the half period ( $\sim 20 \mathrm{kyr})$, which is close to the primary orbital periods of precession. With an example of the Sahara it was shown that sub-Milankovitch variability in vegetation can also induce sub-Milankovitch variability in surface air temperature due to albedo changes.

Due to the simplicity of the vegetation component of CLIMBER-2 the occurrence of sub-Milankovitch variability might be an artifact of the model. In particular the fact that the grass fraction is not directly computed, but is determined as the remaining area after the computation of the tree and desert fraction, might introduce artificial signals. However, the simulated succession of climate and biomes seems realistic: maximum precipitation results in grass mixed with trees with a relatively large water holding capacity, while minimum precipitation results in desert combined with grass area which has a relatively low water holding capacity. In the present model experiments the opposing effects of variations in precipitation and in soil water holding capacity result in variations in runoff at half the precessional period. It is stressed that the proposed mechanism is a hypothesis. Further research is needed to test this hypothesis using more sophisticated vegetation models, which simulate biome types directly in terms of climate.

The difference in detected periods for the African and Asian runoff is caused by the fact that the desert fully covers the Asian monsoon region during strong precession maxima while it only partly covers the African monsoon region (Figs. $4 \mathrm{~b}$ and 5b). This can be explained by the smaller amount of annual precipitation and the lower annual temperature during precession maxima for Asia compared to north Africa. However, this strongly depends on the background climate which is governed by the chosen value of obliquity (here 22.08 degrees), the atmospheric composition (pre-industrial values for carbon dioxide and methane) and the size of the ice sheets (present-day ice sheets). Chang- ing these boundary conditions could easily induce other subMilankovitch variability, for instance a $\sim 5 \mathrm{kyr}$ period in the African runoff and/or no $\sim 5 \mathrm{kyr}$ period in the Asian runoff. Consequently, the simulated sub-Milankovitch periods are only one possible realisation. These periods depend on the background climate that changes when the boundary conditions change.

Including varying ice sheets is not necessary for simulating sub-Milankovitch variability in our model. This is in agreement with Ortiz et al. (1999) who found subMilankovitch variability in the Atlantic Ocean for the period prior to the onset of the glacial cycles at $\sim 2.8$ million years BP. However, this does not imply that ice sheets cannot change the characteristics of sub-Milankovitch variability. For instance, Sun and Huang (2006) found a halfprecession cycle in the loess-soil sequence of the last interglacial reflecting changes in the East Asian summer monsoon circulation. For the last glacial they did not find subMilankovitch variability due to the reduced influence of the summer monsoon on their study area. Another example is the weak sub-Milankovitch variability in a dust record from the eastern Mediterranean Sea from 3 million years BP until the mid-Pleistocene transition (Larrasoaña et al., 2003). During and after the mid-Pleistocene transition, when the amplitude of the Northern Hemisphere ice sheets increases, the subMilankovitch variability gets much stronger. This suggests that the strength of sub-Milankovitch variability depends on the size of the ice sheets. Transient simulations with climate models including an interactive ice sheet model might show this influence of ice sheets on sub-Milankovitch variability.

The sub-Milankovitch periods of about 10 and/or $5 \mathrm{kyr}$ in the Asian and African region are in agreement with proxybased evidence. Sun and Huang (2006) suggest that their periods in the northwestern Chinese Loess Plateau originate from half-precession cycles in the insolation from low latitudes. Our results suggest that their signal could reflect local sub-Milankovitch periods in vegetation and/or runoff.

In marine records sub-Milankovitch periods of $\sim 10 \mathrm{kyr}$ and/or $\sim 5 \mathrm{kyr}$ periods are also found in the Atlantic Ocean (Pokras and Mix, 1987; Hagelberg et al., 1994; McIntyre and Molfino, 1996), in the Mediterranean Sea (Larrasoaña et al., 2003; Becker et al., 2005) and in the Indian Ocean (Pestiaux et al., 1988; Naidu, 1998). In general, these authors explain their signals by variations in the strength of the monsoon (and associated variations in runoff or wind-induced upwelling). We do find some small sub-Milankovitch variability in the annual salinity in the oceanic gridboxes in the vicinity of the monsoon regions. However, directly comparing the sub-Milankovitch variability in marine records to the simulated oceanic variability in the present study is not feasible. Unfortunately, CLIMBER-2 includes a zonally averaged ocean model which does not resolve the wind-driven circulation or small-scale upwelling. Additional simulations with a three-dimensional, high-resolution ocean model should clarify this. 
Acknowledgements. Two anonymous reviewers are thanked for their useful and constructive comments. This work was supported by the Netherlands Organization for Scientific Research (NWO) under a VIDI grant to L. J. Lourens and ISES (EURAF-Project3B.3) to E. Tuenter.

Edited by: J. Hargreaves

\section{References}

Becker, J., Lourens, L. J., Hilgen, F. J., van der Laan, F. J., Kouwenhoven, T. J., and Reichart, G. J.: Late pliocene climate variability on Milankovitch to millennial time scales: A high-resolution study of MIS100 from the Mediterranean., Palaeogeography, Palaeoclimatology, Palaeoecology, 228, 338-360, 2005.

Berger, A., Loutre, M. F., and Mélice, J. L.: Equatorial insolation: from precession harmonics to eccentricity frequencies, Clim. Past, 2, 131-136, 2006,

http://www.clim-past.net/2/131/2006/.

Berger, A. L.: Long-term variations of daily insolation and Quaternary climatic changes, J. Atmos. Sci., 35, 2362-2367, 1978.

Broström, A., Coe, M., Harrison, S. P., Gallimore, R., Kutzbach, J. E., Foley, J., Prentice, I. C., and Behling, P.: Land surface feedbacks and palaeomonsoons in northern Africa, Geophys. Res. Lett., 25, 3615-3618, 1998.

Brovkin, V., Ganopolski, A., and Svirezhev, Y.: A continuous climate-vegetation classification for use in climate-biosphere studies, Ecological Modelling, 101, 251-261, 1997.

Claussen, M., Kubatzki, C., Brovkin, V., and Ganopolski, A.: Simulation of an abrupt change in Saharan vegetation in the midHolocene, Geophys. Res. Lett., 26, 2037-2040, 1999.

Claussen, M., Mysak, L. A., Weaver, A. J., Crucifix, M., Fichefet, T., Loutre, M.-F., Weber, S. L., Alcamo, J., Alexeev, V. A., Berger, A., Calov, R., Ganopolski, A., Goosse, H., Lohmann, G., Lunkeit, F., Mokhov, I. I., Petoukhov, V., Stone, P., and Wang, Z.: Earth system models of intermediate complexity: closing the gap in the spectrum of climate system models, Clim. Dyn., 18, 579-586, 2002.

Cramer, W., Bondeau, A., Woodward, F. I., Prentice, I. C., Betts, R. A., Brovkin, V., Cox, P. M., Fisher, V., Foley, J. A., Friend, A. D., Kucharik, C., Lomas, M. R., Ramankutty, N., Sitch, S., Smith, B., White, A., and Young-Molling, C.: Global response of terrestrial ecosystem structure and function to $\mathrm{CO}_{2}$ and climate change: results from six dynamic global vegetation models, Global Change Biology, 7, 357-373, 2001.

Crowley, T. J., Kim, K.-Y., Mengel, J. G., and Short, D. A.: Modeling the 100,000-Year Climate Fluctuations in Pre-Pleistocene Time Series, Science, 255, 705-707, 1992.

Dickinson, R., Henderson-Sellers, A., Kennedy, P. J., and Wilson, M. F.: Biosphere-Atmosphere Transfer Scheme (BATS) for NCAR CCM, Tech. Rep. NCAR/TN-275-STR, National Center for Atmospheric Research, Boulder, Colo, USA, 69 pp, 1986.

Doherty, R., Kutzbach, J., Foley, J., and Pollard, D.: Fully coupled climate/dynamical vegetation model simulations over Northern Africa during the mid-Holocene, Clim. Dyn., 16, 561-573, 2000.

Ganopolski, A., Kubatzki, C., Claussen, M., Brovkin, V., and Petoukhov, V.: The influence of vegetation-atmosphere-ocean interaction on climate during the mid-Holocene, Science, 280, 1916-1919, 1998a.
Ganopolski, A., Rahmstorf, S., Petoukhov, V., and Claussen, M.: Simulation of modern and glacial climates with a coupled global model of intermediate complexity, Nature, 391, 351-356, 1998b.

Ganopolski, A., Petoukhov, V., Rahmstorf, S., Brovkin, V., Claussen, M., Eliseev, A., and Kubatzki, C.: CLIMBER-2: a climate system model of intermediate complexity. Part II: model sensitivity, Clim. Dyn., 17, 735-751, 2001.

Hagelberg, T. K., Bond, G., and deMenocal, P.: Milankovitch band forcing of sub-Milankovitch climate variability during the Pleistocene, Paleoceanography, 9, 545-558, 1994.

Heslop, D. and Dekkers, M. J.: Spectral analysis of unevenly spaced climatic time series using CLEAN: signal recovery and derivation of significance levels using a Monte Carlo simulation, Phys. Earth Planet. Interiors, 130, 103-116, 2002.

Imbrie, J., Boyle, E. A., Clemens, S. C., Duffy, A., Howard, W. R., Kukla, G., Kutzbach, J., Martinsson, D. G., McIntyre, A., Mix, A. C., Molfino, B., Morley, J. J., Peterson, L. C., Pisias, N. G., Prell, W. L., Raymo, M. E., Shackleton, N. J., and Toggweiler, J. R.: On the structure and origin of major glaciation cycles 1 . Linear responses to Milankovitch forcing, Paleoceanography, 7, 701-738, 1992.

Jackson, C. S. and Broccoli, A. J.: Orbital forcing of Arctic climate: mechanisms of climate response and implications for continental glaciation, Clim. Dyn., 21, 539-557, doi:10.1007/s00382-0030351-3, 2003.

Kubatzki, C., Montoya, M., Rahmstorf, S., Ganopolski, A., and Claussen, M.: Comparison of the last interglacial climate simulated by a coupled global model of intermediate complexity and an AOGCM, Clim. Dyn., 16, 799-814, 2000.

Larrasoaña, J. C., Roberts, A. P., Rohling, E. J., Winkelhofer, M., and Wehausen, R.: Three million years of monsoon variability over the northern Sahara, Clim. Dyn., 21, 689-698, doi:10.1007/s00382-003-0355-z, 2003.

Le Treut, H. and Ghil, M.: Orbital forcing, climatic interactions, and glaciation cycles, J. Geophys. Res., 88, 5167-5190, 1983.

McIntyre, A. and Molfino, B.: Forcing of Atlantic equatorial and subpolar millenial cycles by precession, Science, 274, 18671870, 1996.

Naidu, P. D.: Driving forces of Indian summer monsoon on Milankovitch and sub-Milankovitch time scales: A review, Journal Geological Society of India, 52, 257-272, 1998.

Ortiz, J., Mix, A., Harris, S., and O'Connell, S.: Diffuse spectral reflectance as a proxy for percent carbonate content in North Atlantic sediments, Paleoceanography, 14 , 171-186, doi:10.1029/1998PA900021, 1999.

Pestiaux, P., van der Mersch, I., and Berger, A.: Paleoclimate variability at frequencies ranging from 1 cycle per 10000 years to 1 cycle per 1000 years: Evidence for nonlinear behaviour of the climate system, Climatic Change, 12, 9-37, 1988.

Petoukhov, V., Ganopolski, A., Brovkin, V., Claussen, M., Eliseev, A., Kubatzki, C., and Rahmstorf, S.: CLIMBER-2: a climate system model of intermediate complexity. Part I: model description and performance for present climate, Clim. Dyn., 16, 1-17, 2000.

Pokras, E. M. and Mix, A. C.: Earth's precession cycle and Quaternary climatic change in tropical Africa, Nature, 326, 486-487, 1987.

Roberts, D. H., Lehar, J., and Dreher, J. W.: ime-Series Analysis with Clean. 1. Derivation of A Spectrum, Astronomical Journal, 
93, 968-989, 1987.

Rodríguez-Tovar, F. J. and Pardo-Igúzquiza, E.: Strong evidence of high-frequency (sub-Milankovitch) orbital forcing by amplitude modulation of Milankovitch signals, Earth Planet. Sci. Lett., 210, 179-189, doi:10.1016/S0012-821X(03)00131-6, 2003.

Saltzman, B. and Sutera, A.: A model of the internal feedback system involved in late Quaternary climatic variations, J. Atmos. Sci., 41, 736-745, 1984.

Short, D. A., Mengel, J. G., Crowley, T. J., Hyde, W. T., and North, G. R.: Filtering of Milankovitch cycles by Earth's geography, Quat. Res., 35, 157-173, 1991.

Steenbrink, J., Kloosterboer-van Hoeve, M. L., and Hilgen, F. J.: Millennial-scale climate variations recorded in Early Pliocene colour reflectance time series from the lacustrine Ptolemais Basin (NW Greece), Global and Planetary Change, 36, 47-75, 2003.
Stocker, T. F., Wright, D. G., and Mysak, L. A.: A zonally averaged coupled ocean-atmosphere for paleoclimate studies, J. Climate, 5, 773-797, 1992.

Sun, J. and Huang, X.: Half-precessional cycles recorded in Chines loess: response to low-latitude insolation forcing during the last interglaciation, Quat. Sci. Rev., 25, 1065-1072, 2006.

Tuenter, E., Weber, S. L., Hilgen, F. J., and Lourens, L. J.: The response of the African summer monsoon to remote and local forcing due to precession and obliquity, Global and Planetary Change, 36, 219-235, 2003.

Tuenter, E., Weber, S. L., Hilgen, F. J., Lourens, L. J., and Ganopolski, A.: Simulation of climate phase lags in the response to precession and obliquity forcing and the role of vegetation, Clim. Dyn., 24, 279-295, doi:10.1007/s00382-004-0490-1, 2005. 